\title{
An Autoethnography of Vicarious Trauma and Vicarious Growth in the Context of Rehabilitation Counseling
}

\author{
Azam Naghavi ${ }^{1,{ }^{*}}$ and Samaneh Salimi ${ }^{1}$ \\ ${ }^{1}$ Department of Counseling, Faculty of Education and Psychology, University of Isfahan, Isfahan, Iran \\ "Corresponding author: Azam Naghavi, Assistant Professor, Department of Counseling, Faculty of Education and Psychology, University of Isfahan, Isfahan, Iran. Tel: \\ +98-9132133455, Fax: +98-3136683107, E-mail: az.naghavi@edu.ui.ac.ir
}

Received 2017 October 09; Revised 2017 November 03; Accepted 2018 February 03.

\begin{abstract}
Background: Mental health professionals including rehabilitation counselors are often exposed to vicarious trauma, while they work with traumatized clients.

Objectives: The current study aimed at explaining the experiences of exposure to vicarious trauma and its consequences for rehabilitation counselors as well as the experience of vicarious growth.

Methods: The current study employed a collaborative autoetnographic approach to describe the experiences of working with traumatized clients. Collaborative autoethnography is a type of qualitative research method that allows two or more researchers to utilize ethnography and autobiography collaboratively to explain similar experiences. In this method, researchers collect data from their own life stories and analyze the data using various types of qualitative analyses. To analyze the current study data, a thematic analysis approach was employed.

Results: It was found that lack of experience in working with difficult cases, lack of access to supervision, and a lack of vicarious trauma-related knowledge were major contributors to the experience of vicarious trauma. On the other hand, journal writing, visiting a counselor, peer support, and gaining knowledge were useful to overcome this stress. The next findings showed that although visiting traumatized clients may lead to experiencing vicarious trauma, it can also lead to experiencing vicarious growth. Vicarious trauma helped to be more mindful about life and death, cherish the family and friends, and experience growth.

Conclusions: Rehabilitation counselors might experience both vicarious trauma and vicarious posttraumatic growth. The experience of vicarious trauma has a negative effect on counselors and they should employ self-care strategy to mitigate the negative results of exposure to traumatic experiences of others and if they wish to experience vicarious growth.
\end{abstract}

Keywords: Mental Health Rehabilitation, Psychological Trauma, Qualitative Research, Rehabilitation Counselor, Stress Disorder

\section{Background}

Trauma work can be traumatic(1). Some researchers argue exposure to trauma and trainings. Munger et al. (2) also found that lack of attention to vicarious trauma might disrupt the ability to show empathy and decrease the quality of care and treatment.

Vicarious trauma (VT) is one of the many concepts constructed in an attempt to conceptualize the negative impact of working with traumatized clients. This concept was introduced by McCann and Pearlman and is the transformation that occurs within the therapist (or other trauma worker) as a result of empathic engagement with client's trauma experiences and their sequel (3). VT changes the suffering of other people and may lead to burnout, secondary stress, compassion fatigue, and vicarious traumatization; all of these are considered as hazards of help- ing professions (4-7). Iqbal (5) in ethical considerations of counselling posed several questions about the ethical issues of working with clients by counsellors that were vicariously traumatized, but did not receive vicarious-trauma training. VT changes the perception of the therapist towards the self, others, and the world. Strong emotional reactions, intrusive thoughts, a disruption in belief about the self, others, and the world are some of the alerting signs of this concept (3).

Research about vicarious trauma attracted considerable attention in recent years. This phenomenon is mostly researched by members of helping professions such as social workers $(8,9)$, medical staff $(10)$, mental health professionals (11), and service providers to refugees and survivors of torture $(12,13)$. Research shows that people working with traumatized clients may experience cognitive, emotional, physical, and behavioral changes after listening to trau- 
matic narratives. These professionals may face negative changes in their cognitive schemas about world safety (14), existential questions (15), experience increasing awareness of vulnerability, and a feeling of being at risk (16). They would also experience emotional signs such as anger, frustration and hopelessness (17), sadness and shock (18), and feelings of detachment (16).

Although vicarious traumatization is one of the effects of trauma work, it is not the only impact of it. One important concept around trauma work is the positive aspect of this work under the concept of vicarious post-traumatic growth (VPTG). This concept can be explained within the framework of post-traumatic growth (PTG) introduced by Tedeschi and Calhorn (19). Based on PTG theory, survivors of traumatic events can experience positive changes in interpersonal relations, self-perception, and philosophy of life. This growth occurs in five aspects of life: a better relationship with others, more personal strength, positive spiritual changes, appreciation of life, and discovering new possibilities. These changes are not limited to the clients; professionals also may vicariously experience growth as a consequence of their work with traumatized clients experiencing PTG.

Arnold et al. (20) developed the concept of PTG into VPTG as a process in which the therapists may experience changes in self, spirituality, their life-view, their evaluation of life, and their evaluation of fundamental human nature similar to survivors of traumatic experiences.

Studies show similar findings that support the model by Arnold et al. (20) of VPTG. For instance, Hyatt-Burkhart (21) found that mental health professionals experienced some positive changes including the ability to better adapt to their lives. Social workers in a hospital in Melbourne reported that apart from vicarious trauma, they also found positive aspects of their work such as more growth as consequences of accepting death as a worldwide phenomenon (22). Certified nurse-midwives (23), nurses (24), psychiatrist nurses (25), mental health nurses (21), and interpreters for refugees (18), all reported they had experienced growth, while working with traumatized clients. The Iranian study of vicarious trauma and vicarious growth is in its early steps.

\section{Objectives}

The current study aimed at explaining the experiences of exposure to vicarious trauma and its consequences for rehabilitation counsellors as well as the experience of vicarious growth.

\section{Materials and Methods}

A collaborative autoethnography approach (CAE) (26) was employed to collect and analyze the data for the current study. Autoethnography is an autobiographical genre of writing and research (27). Autoethnography is an opportunity for professionals to scientifically explore, explain, and analyze their own experiences. Autoethnography is an incorporation of auto, ethno, and graphy that places the self (auto) in a sociocultural context (ethno) and explains (graphy) it (28). Collaborative autoethnography approach is a type of autoethnography in which a team of two or more researchers use their experiences around an issue. Chang et al. (26) define collaborative autoethnography approach as "a qualitative research method that is simultaneously collaborative, autobiographical, and ethnographic" (p.17). In collaborative autoethnography approach, every researcher has her voice in harmony with others to explain a phenomenon. Autoethnography can be emancipating and healing for both authors and other people in similar situations. Freidan (28) in 1960s found that many American housewives do not talk about their experiences of being trapped in housework and they thought that they were alone in this experience. She started to write and share these experiences and her writings were healing for many females, and a starting point for many cultural movements around females' rights. Although autoethnography can be written by only one participant that is the author (29-31), according to Chang et al. (26), sample size in collaborative autoethnography can be as few as two and as many as 11 researchers and two-person autoethnography is more common. In the current study the most common type of collaborative autoethnography sample size, which is the twoperson method, was employed.

\subsection{Data Collection}

Autoethnography uses common methods of data collection in qualitative research. The most common type of data in autoethnography is personal narratives and autobiographical contents. Data from external sources such as family, friends, and colleagues, and documents such as diary writings can also be analyzed as data. Application of other means of data collection such as self-reflection and interviewing each other is also recommended. In collaborative autoethnography, researchers should have multiple discussions around these data and in an iterative process collect and analyze data. The current study followed suggestions by Chang et al. (26), around data collection. Both of the authors wrote their narratives around the counselling experiences in Isfahan, Iran, covering the last ten years of work as counsellors. Then, in a six-month iterative process, authors had several discussion sessions around 
these writings to clarify their points. In these sessions both of them talked through their experiences in details and clarified what they meant by their writings. The process of data collection and analysis concurrently happened during these sessions.

Muncey (32) states that since autoethnography is the study of self, in many academic institutions there is not a need to get a formal ethics approval from an ethics committee; however, this does not mean that it is not needed to follow ethical considerations in autoethnography and CAE. To ensure ethics, as Ellis (33) suggested, no names or identifiers for other people that played a role in the narratives were used. Authors were selective about what to include and what to omit in the final report to preserve the privacy of involuntary participants.

\subsection{Data Analysis}

A thematic analysis approach was employed to identify themes from the data. Coding of the data occurred during data collection by both authors independently and a professor in counselling checked the quality of the first round of coding. There were regular sessions to talk about open codes, categories, and findings of the primary themes; in case of disagreements, issues were resolved through discussions. The major concluded themes were structural factors relating to vicarious trauma, coping strategies, and vicarious growth.

\section{Results}

\subsection{The Start of a Journey}

As Teunissen et al. (34) stated, the first finding in an autoethnography research is the narrative itself. To explain these narratives, a first person voice was employed for the first author and a third person voice for the second author. Structural factors such as lack of experience of working with traumatized clients and a limited access to supervisor were some of the major structural categories found.

The first author's experience of vicarious trauma did not start suddenly, nor did it replicate any major trauma history in her life. Research findings around the relationship between a history of trauma and vicarious trauma had contradictory results $(10,35)$. In line with findings that show no relationship between the two, the first author did not have any major trauma in her life or did not remember. The first and most traumatic event in the first author's life happened vicariously when working as a young counsellor after graduating from Masters in counselling and visited a traumatized school child that was repeatedly sexually abused by a relative. At that time there was not a formal supervision program for Iranian counselling graduates. The first encounter with a traumatized child was just out of my empathic ability. "I could do nothing", I repeated to myself during the session. I felt misery. At the end of the session I referred him to a psychiatrist. The next child abuse cases had the same impact on me and I had the same reaction: avoidance of working with them. I just kept referring them to others.

In contrast to my history, Samaneh, the second author of this paper narrated some stories that she perceived them as traumatic. Samaneh was just 11 when the school principal asked her to talk to a sad and lonely classmate. Samaneh says:

She was a short girl with beautiful sad eyes. Her hands were full of scars. One day the principal told me in private: "you should talk to your friend. She has some problems, but she does not trust me. She had said to a teacher that you are the only person she wanted to talk to".

Samaneh proudly went to do her mission and in the next class time, both of them were allowed to go out and talk. The principle asked Samaneh to start with some general questions about her friend's family and then ask her about her problems. But Samaneh made up her question and suddenly said:

I'd like to be a pilot, what about you? "I'll be paralyzed", the girl said.

Samaneh was shocked by this answer and did not know how to proceed with the conversation. She found out that the girl's mother and uncle were paralyzed due to an illness. The girl surely thought that she would not be able to walk when she got older. After listening to her friends for two hours she panicked to lose her ill mother. She ran all the way to home with intrusive thoughts and fear about her mother's health. Samaneh considers this event as her first traumatic event; "I was too young to be a counsellor. It was not fair to me", she said.

The rest of Samaneh narrative was similar to mine. We both were young counsellors who had to face difficult cases without enough trauma knowledge or professional support.

\subsection{What's Wrong with Me?}

Lack of vicarious trauma-related knowledge was another structural factor found to be related to the negative effects of experiencing vicarious trauma. Both of us experienced intrusive thoughts, avoidance and a change in our ideas about the self, others and the world, but we had no clue what was happening to us.

For example, for a long time after meeting some sexually abused children, I had nightmares about the details of the events and would also daydream about the pain and suffering they went through.

Samaneh also experienced intrusive thoughts when her client's mother passed away. She mourned just like her 
client and condemned God for his unfair actions. She had intrusive imagery of herself with an amputee hand and had nightmares about losing her body parts and burying them.

Both of us experienced anxiety in our work with traumatized clients or people with disability. We faced death, mortality, and the human's shaking status in the world in our practice. Both of us experienced anger towards the world, pessimistic approach towards others, a lower value for our "self", ruminations about the traumatic events we had heard, feeling of vulnerability, hopelessness, helplessness, lack of power, lack of self-confidence in counselling, sleep disturbance, and even physical fatigue without a known reason.

Both of us decided to leave our jobs at some points of our career; I decided to stop visiting clients for a while and focus on teaching and continue my studies, Samaneh also though about leaving her counselling job, but we could never quit helping others altogether. Samaneh said: "Many people suggested me to quit working with hard clients, but I thought I had to continue, Ifelt like a wounded pilot that knows she must not fall".

\subsection{So What Should I Do?}

Reviewing or written reflections helped us to identify how we could overcome negative effects of vicarious trauma, hence, the second themes we have found in our data was coping strategies. Journal writing, yoga, meditation, visiting a counsellor, peer support, and learning about vicarious trauma were some of the self-care strategies we employed. These techniques were recommended to us both in formal situations such as counselling sessions or in informal situations by peers. Some of these self-care strategies also came from our readings in the field of vicarious trauma.

\subsection{Rebuilding a Shattered Life-View}

Another major theme we found in the discussions was that working with traumatized clients does not always lead to negative feelings and thoughts. It seems that both of us experienced some personal changes emerging from approaching resilient and strong clients. During our practice, we think we deeply changed and evolved from a vulnerable individual to an empowered person.

Samaneh wrote: "Thinking about mortality gave me existential anxiety. This anxiety, however, leads me to think that I do not have enough time to enjoy being with others so I have to make the most out of it".

We both started to appreciate what we had, our families, friends, health and security. Watching our clients' resilience and observing their strengths to get back on track with all their difficulties, trauma and disabilities helped us to be more aware of the human's strength. "If they could make it, I can make it"; I thought.

During our exposure to traumatized clients, our philosophy of life changed dramatically. We saw people whose self-concept was not dependent on external variables such as family, wealth, or even health. We are more mindful about the symptoms and signs we are experiencing, and know that there is no end to this story.

\section{Discussion}

Studies show that members in helping careers, such as mental health workers, medical staff, social workers and rehabilitation professionals may experience vicarious trauma. Vicarious trauma, which is considered an occupational hazard, may lead to a disruption in building an empathic relationship (13); a disruption in cognition about self, negative belief about self, a disruption in self-esteem as well as experiences in changing the view towards self, others, and the world. However, researchers found that workers in helping professions can also experience growth as a consequence of facing and working with traumatized clients (3).

Similar to the findings of Finklestein et al. (11), the authors' experiences of VT were mostly related to the education and lack of professional supports. Both of us started to work with difficult cases early in the career while had no enough expertise and formal and structured professional supervision. Meeting traumatized people and clients with disability took a toll on our emotional wellbeing and on our cognition and made us vulnerable to emotional distress. This shows the importance of adding vicarious trauma knowledge and supervision for young practitioners.

The current study found vicarious trauma and VPTG as Cohen and Collens (36) found in their meta synthesis: "growth can occur, while still feeling some level of distressing emotions" (p.577). The authors experienced both concepts at the same time.

While working as rehabilitation counsellors authors experienced change in their life philosophy and meaning. It was in line with Barrington and the Shakespeare-Finch (13) findings that showed therapists experienced some changes as a consequence of their engagement in working with refugees and victims of torture. Observance of resilience and growth among clients brought the authors hope and optimism as Splevins et al. (18), and Cohen and Collens (36) also mentioned in their studies.

In line with other research, seeking help and support from others especially supervisors and counsellors and 
peers (18), being mindful about illness and death and accepting these facts (22), meaning making for the work (13), more experience over time, and (10) using self-care behaviors including yoga and meditation $(18,35)$ were some of the coping strategies that the authors employed in order to overcome vicarious trauma.

\subsection{Conclusion}

The current study provided an opportunity to a deeper understanding of the experiences of two counsellors working with traumatized clients or people with chronic illnesses or some kind of disabilities. In line with previous research, the current study found that working with traumatized clients or people that need rehabilitation can lead to vicarious trauma for counsellors and it may negatively affect them. People may use different coping strategies to overcome these negative effects and authors employed strategies such as using formal and informal supports. It was also found that listening to traumatic events and how people overcome the aftermath of trauma may lead to vicarious growth as well.

\section{Acknowledgments}

Authors would like to thank Professor Mohammad Reza Abedi for his insightful comments during coding and data analysis.

\section{Footnotes}

Authors' Contribution: Both authors contributed in data collection, coding, and analysis of the data. First author was the main writer of the final report.

Declaration of Interest: The authors declared no conflict of interest.

Funding/Support: This research received no specific grant from any funding agency in the public sector.

\section{References}

1. Levers L. Trauma counseling: Theories and intervention. New York: Springer; 2012.

2. Munger T, Savage T, Panosky DM. When caring for perpetrators becomes a sentence: Recognizing vicarious trauma. JCorrect Health Care. 2015;21(4):365-74. doi: 10.1177/1078345815599976. [PubMed: 26377382].

3. Pearlman LA, Mac Ian PS. Vicarious traumatization: An empirical study of the effects of trauma work on trauma therapists. Prof Psychol Res Pr. 1995;26(6):558-65. doi: 10.1037/0735-7028.26.6.558.

4. Skovholt TM. The resilient practitioner: Burnout and compassion fatigue prevention and self-care strategies for the helping profession. 3rd ed. New York: Routledge; 2016. doi: 10.4324/9781315737447.

5. Iqbal A. The ethical considerations of counselling psychologists working with trauma: Is there a risk of vicarious traumatisation? Counsel Psychol Rev. 2015;30(1):44-51.
6. Palm KM, Polusny MA, Follette VM. Vicarious traumatization: Potential hazards and interventions for disaster and trauma workers. Pre hosp Disaster Med. 2004;19(1):73-8. doi: 10.1017/s1049023x00001503.

7. Morrissette PJ. Self-supervision: A primer for counsellors and helping professionals. New York: Taylor \& Francis; 2001.

8. Blome WW, Safadi NS. Shared vicarious trauma and the effects on Palestinian social workers. Illness Crisis Loss. 2016;24(4):236-60. doi: $10.1177 / 1054137315597176$

9. Michalopoulos LM, Aparicio E. Vicarious trauma in social workers: The role of trauma history, social support, and years of experience. J Aggression Maltreatment Trauma. 2012;21(6):646-64. doi: 10.1080/10926771.2012.689422.

10. Mairean C, Turliuc MN. Predictors of vicarious trauma beliefs among medical staff. J Loss Trauma. 2013;18(5):414-28. doi: 10.1080/15325024.2012.714200.

11. Finklestein M, Stein E, Greene T, Bronstein I, Solomon Z. Posttraumatic stress disorder and vicarious trauma in mental health professionals. Health Soc Work. 2015;40(2):e25-31. doi: 10.1093/hsw/hlv026.

12. Mishori R, Mujawar I, Ravi N. Self-reported vicarious trauma in asylum evaluators: A preliminary survey. J Immigr Minor Health. 2014;16(6):1232-7. doi:10.1007/s10903-013-9958-6.

13. Barrington AJ, Shakespeare-Finch J. Working with refugee survivors of torture and trauma: An opportunity for vicarious post-traumatic growth. Counsell Psychol Q. 2013;26(1):89-105. doi: 10.1080/09515070.2012.727553.

14. Pistorius KD, Feinauer LL, Harper JM, Stahmann RF, Miller RB. Working with sexually abused children. Am J Fam Ther. 2008;36(3):181-95. doi: 10.1080/01926180701291204.

15. Goldblatt H, Buchbinder E, Eisikovits Z, Arizon-Mesinger I. Between the professional and the private: The meaning of working with intimate partner violence in social workers' private lives. Violence Against Women. 2009;15(3):362-84. doi: 10.1177/1077801208330436. [PubMed: 19131561].

16. Clemans SE. Life changing: The experience of rape-crisis work. Affilia. 2016;19(2):146-59. doi: 10.1177/0886109903262758.

17. Satkunanayagam K, Tunariu A, Tribe R. A qualitative exploration of mental health professionals' experience of working with survivors of trauma in Sri Lanka. Int J Cult Ment Health. 2010;3(1):43-51. doi: $10.1080 / 17542861003593336$.

18. Splevins KA, Cohen K, Joseph S, Murray C, Bowley J. Vicarious posttraumatic growth among interpreters. Qual Health Res. 2010;20(12):170516. doi: 10.1177/1049732310377457. [PubMed: 20663936].

19. Tedeschi RG, Calhoun LG. The posttraumatic growth inventory: Measuring the positive legacy of trauma.J Trauma Stress. 1996;9(3):455-71. doi: 10.1002/jts.2490090305. [PubMed: 8827649].

20. Arnold D, Calhoun LG, Tedeschi R, Cann A. Vicarious posttraumatic growth in psychotherapy.JHumanistic Psychol. 2005;45(2):239-63. doi: $10.1177 / 0022167805274729$.

21. Hyatt-Burkhart D. The experience of vicarious posttraumatic growth in mental health workers. J Loss Trauma. 2014;19(5):452-61. doi: 10.1080/15325024.2013.797268.

22. Joubert L, Hocking A, Hampson R. Social work in oncologyManaging vicarious trauma-The positive impact of professional supervision. Soc Work Health Care. 2013;52(2-3):296-310. doi: 10.1080/00981389.2012.737902. [PubMed: 23521390].

23. Beck CT, Rivera J, Gable RK. A mixed-methods study of vicarious posttraumatic growth in certified nurse-midwives. J Midwifery Womens Health. 2016;62(1):80-7. doi: 10.1111/jmwh.12523. [PubMed: 27779827].

24. Mairean C. Secondary traumatic stress and posttraumatic growth: Social support as a moderator. Soc Sci J. 2016;53(1):14-21. doi: 10.1016/j.soscij.2015.11.007.

25. Zerach G, Shalev TBI. The relations between violence exposure, posttraumatic stress symptoms, secondary traumatization, vicarious post traumatic growth and illness attribution among psychiatric nurses. Arch Psychiatr Nurs. 2015;29(3):135-42. doi: 10.1016/j.apnu.2015.01.002. 
26. Chang H, Ngunjiri F, Hernandez K. Collaborative autoethnography. Walnut Creek, CA: Left Coast Press; 2012.

27. Ellis C, Bouchner A. Autoethnography, personal narrative, reflexivity. In: Denzin N, Lincoln Y, editors. Handbook of qualitative research. 2nd ed. Thousand Oaks, CA: Sage; 2000.

28. Ellis C,Adams T, Bouchner AP. Autoethnography: An overview. Hist Soc Res. 2011;35(4):273-90. doi: 10.12759/hsr.36.2011.4.273-290.

29. Ellis C. Final negotiations: A story of love, and chronic illness. Philadelphia, PA: Temple University Press; 1995.

30. Halley J. To speak of my mother. Qual Inq. 2003;9(1):49-56. doi: $10.1177 / 1077800402239339$.

31. Camden-Pratt CE. Daughters of persephone: Legacies of maternal madness. Sydney, Australia: Western Sydney University; 2002.
32. Muncey T. Creating autoethnographies. London, UK: Sage Publication; 2010. doi: $10.4135 / 9781446268339$.

33. Ellis C. Telling secrets, revealing lives: relational ethics in research with intimate others. Qual Inq. 2007;13(1):3-29. doi: $10.1177 / 1077800406294947$.

34. Teunissen GJ, Visse MA, Abma TA. Struggling between strength and vulnerability, a patients' counter story. Health Care Anal. 2015;23(3):288-305. doi:10.1007/s10728-013-0254-3.

35. Jordan K. Vicarious trauma: Proposed factors that impact clinicians. J Fam Psychother. 2010;21(4):225-37. doi:10.1080/08975353.2010.529003.

36. Cohen K, Collens P. The impact of trauma work on trauma workers: A metasynthesis on vicarious trauma and vicarious posttraumatic growth. Psychol Trauma. 2013;5(6):570-80. doi:10.1037/a0030388. 